\title{
Clinlcopathological Study of Ovarian Cancer: A Multi Centered Study
}

\author{
Deeba $\mathrm{F}^{1}$, Alam ABMM², Banu $\mathrm{J}^{3}$
}

\begin{abstract}
Background: Ovarian cancer is one of the leading causes of morbidity and mortality. Objectives: The purpose of the present study was to find out clinic-demographic and histopathological variants of ovarian cancer. Methodology: This cross-sectional study was conducted in the Department of Obstetrics and Gynaecology at four largest tertiary care Hospitals in Dhaka city from January 2008 to December 2009. Clinically diagnosed and histopathologically confirmed ovarian cancer patients were included in this study. Result: Histopathological confirmed 28 patients of ovarian cancer were enrolled in this study. The mean age $( \pm \mathrm{SD})$ was $40.6( \pm 12.5)$ years (Range 13 to 63 years). Lower abdominal lump $(71.4 \%)$ was the most common symptoms. Family history $(14.0 \%)$ and multiparty $(53.0 \%)$ were also associated with ovarian cancer. Among 28 malignant tumors cases serious cyst adenocarcinoma (57.1\%) was the most common followed by mucinous cyst adenocarcinoma (17.9\%), dysgerminoma (7.1\%), adenocarcinoma of ovary (7.1\%), ovarian choriocarcinoma (3.6\%) and endometriod adeno carcinoma (3.6\%). High serum CA125 was found in 78.0\% cases. Conclusion: Lower abdominal lump, multiparity and positive family history are the common clinical findings of ovarian cancer. Both serous and mucinous cyst adenocarcinoma are the common varient of ovarian cancer found in this study. [J Shaheed Suhrawardy Med Coll, 2013;5(1):3-6]
\end{abstract}

Key words: Ovarian cancer, adenocarcinoma, choriocarcinoma, mucinous cyst adenocarcinoma

(Received: December 2012; Revised: March 2013; Accepted: May 2013)

\section{Introduction}

Ovarian cancer is the leading cause of death among gynecologic malignancies ${ }^{1}$. It is the $5^{\text {th }}$ most common cancer among women in the $\mathrm{UK}^{2}$. It constitutes about $15.0 \%-20.0 \%$ of genital malignancies ${ }^{2}$. Majority of the ovarian tumors are benign having cystic, solid or mixed characteristics ${ }^{3}$. The remaining $20.0 \%$ of these tumors are malignant in nature leading to fatal prognosis ${ }^{3}$. Ovarian cancer is associated with poor prognosis ${ }^{3}$ in contrast to other malignancies. It remained poor despite the new chemotherapeutic treatment modalities ${ }^{3-4}$. This poor prognosis has usually been attributed to the fact that at the time of diagnosis about $70.0 \%$ of ovarian cancers have already been widespread intraperitoneal metastases ${ }^{5}$ and five years survival is only $28.0 \%{ }^{6}$. Furthermore, the lifetime risk of development of ovarian cancer is $5.0 \%-7.0 \%{ }^{2}$. Due to the fatal outcome of this disease, early and accurate diagnosis of ovarian tumor is needed.

It gives an increasing challenge to the gynaecological oncologists who are frustrated by the paucity of knowledge of the aetiological factors in ovarian cancer and by the failure to achieve any dramatic reduction in mortality due to this cancer during past 6 decades $^{7}$. The early detection and assessment of ovarian malignancy are an important part of gynaecological practice. This study was carried out with an aim to see the clinicopathological findings and sociodemographic variables of ovarian cancer patients.

\section{Methodology}

This cross-sectional study was carried out in the Department of Obstetrics and Gynaecology at Bangabandhu Sheikh Mujib Medical University (BSMMU), Dhaka Medical College Hospital (DMCH), Dhaka and Bangladesh Medical College Hospital (BMCH), Dhaka and Shaheed Suhrawardy Medical College (ShSMCH), Dhaka from January 2008 to December 2009 for a period of two (2) years. These four tertiary care hospitals in Dhaka city are the largest tertiary care hospitals situated at different locations of the city. Majority patients were visited in these hospitals. Thus the study population of this present study represented the whole Dhaka city. Clinically diagnosed patients of ovarian cancer

1. Dr. Farzana Deeba, Assistant Professor, Infertility, Department of Gynaecology and Obstetrics, Bangabandhu Sheikh Mujib Medical University, Dhaka

2. Prof. ABM Muksudul Alam, Professor \& Head, Department of Anaesthesia, Shaheed Suhrawardy Medical College, Dhaka

3. Dr. Jesmin Banu, Assistant Professor, Infertility, Department of Gynaecology and Obstetrics, Bangabandhu Sheikh Mujib Medical University, Dhaka

\section{Correspondence}

Dr. Farzana Deeba, Assistant Professor, Department of Gynaecology and Obstetrics, Bangabandhu Sheikh Mujib Medical University, Dhaka, Bangladesh; Email: deeba_51@yahoo.com; Cell No.: +8801711535404 
who were admitted in the Department of Obstetrics and Gynaecology at BSMMU, DMCH, BMCH and ShSMCH at any age were enrolled for the study. After proper counseling and informed consent, their sociodemographic histories were taken. Different biochemical values including serum CA-125 were measured. Then histopathological examinations were done to confirm ovarian cancer. Computer based statistical analysis were carried out with appropriate techniques and systems. All data were recorded systematically in preformed data collection form (questionnaire) and quantitative data were expressed as mean and standard deviation and qualitative data were expressed as frequency distribution and percentage. Statistical analysis was performed by using window based computer software devised with Statistical Packages for Social Sciences (SPSS-19) (SPSS Inc, Chicago, IL, USA). The summarized data was interpreted accordingly and was then presented in the form of tables.

\section{Results}

A total number of 28 cases were examined. Majority of the patients were in the age group of 41 to 50 years of age which was $10(35.7 \%)$ cases. The mean age was $40.6 \pm 12.5$ years with ranged from 13 to 63 years (Table 1)

Table 1: Age Distribution of the Study Population $(n=28)$

\begin{tabular}{lcc}
\hline Age Group & Frequency & Percentage \\
\hline$\leq 30$ years & 4 & 14.3 \\
31-40 years & 8 & 28.6 \\
41-50 years & 10 & 35.7 \\
51-60 years & 4 & 14.3 \\
61-70 years & 2 & 7.1 \\
Total & $\mathbf{2 8}$ & $\mathbf{1 0 0 . 0}$ \\
\hline
\end{tabular}

$*$ Mean $\pm \mathrm{SD}=40.6 \pm 12.5$ years (Range $13-63$ years)

The symptoms among the study subjects were observed and found that majority were presented with abdominal lump which was 20(71.4\%). Weight loss was found in $17(60.7 \%)$ cases. Heaviness were found in 13(46.4\%) cases. However, $11(39.3 \%)$ cases complains of pain. Nearly one third $(32.1 \%)$ of the subjects had others symptoms (Table 2 ).

Table 2: Distribution of the Study Subjects According to Symptoms $(n=28)$

\begin{tabular}{lcc}
\hline Symptoms & Frequency & Percentage \\
\hline Lump & 20 & 71.4 \\
Weight loss & 17 & 60.7 \\
Heaviness & 13 & 46.4 \\
Pain & 11 & 39.3 \\
Others & 9 & 32.1 \\
Total & $\mathbf{2 8}$ & $\mathbf{1 0 0 . 0}$ \\
\hline
\end{tabular}

The history of taking fertility drugs was reported by $16(53.3 \%)$ cases. On the other hand $4(14.3 \%)$ cases had positive family history. It was observed that $10(35.7 \%)$ cases used oral contraceptive and $16(53.3 \%)$ cases have given the history of high parity (Table 3 ).

Table 3: Fertility Drugs and Family History among the Ovarian Cancer Patients $(n=28)$

\begin{tabular}{lcc}
\hline Associated History & Frequency & Percentage \\
\hline Fertility drugs $(\mathrm{n}=28)$ & 6 & 21.4 \\
Family history $(\mathrm{n}=28)$ & 4 & 14.3 \\
OCP intake $(\mathrm{n}=28)$ & 10 & 35.7 \\
High Parity $(\mathrm{n}=28)$ & 16 & 53.3 \\
\hline
\end{tabular}

$* \mathrm{OCP}=$ oral contraceptive pill

Size of tumor was measured in this study. It was observed that $2(7.1 \%)$ cases had 1 to $3 \mathrm{~cm}, 4(14.3 \%)$ cases had 3.1 to $5 \mathrm{~cm}, 17(60.7 \%)$ cases had 5.1 to $10 \mathrm{~cm}$ and $5(17.9 \%)$ cases had more than $10 \mathrm{~cm}$ tumor size (Table 4$)$.

Table 4: Size of the tumor among study subjects $(n=28)$

\begin{tabular}{lcc}
\hline Size of Tumor & Frequency & Percentage \\
\hline $1-3 \mathrm{~cm}$ & 2 & 7.1 \\
$3.1-5 \mathrm{~cm}$ & 4 & 14.3 \\
$5.1-10 \mathrm{~cm}$ & 17 & 60.7 \\
$>10 \mathrm{~cm}$ & 5 & 17.9 \\
Total & $\mathbf{2 8}$ & $\mathbf{1 0 0 . 0}$ \\
\hline
\end{tabular}

In this study 28 malignant tumors were found of which $16(57.1 \%)$ cases were serous cyst adenocarcinoma, $5(17.9 \%)$ cases were mucinous cyst adenocarcinoma, $1(3.6 \%)$ case ovarian choriocarcinoma, $1(3.6 \%)$ case was endometrioid carcinoma, 2(7.1\%) cases were dysgerminoma and $2(7.1 \%)$ cases were adenocarcinoma of ovary (Table 5$)$.

Table 5: Histopathological categories of malignant tumors among the Study Population $(n=28)$

\begin{tabular}{lcc}
\hline Malignant Tumor & Frequency & Percentage \\
\hline Serous Cyst Adenocarcinoma & 16 & 57.1 \\
Mucinous Cyst Adenocarcinoma & 6 & 21.4 \\
Ovarian Choriocarcinoma & 1 & 3.6 \\
Endometrioid Carcinomas & 1 & 3.6 \\
Dysgerminoma & 2 & 7.1 \\
Adenocarcinoma of ovary & 2 & 7.1 \\
Total & $\mathbf{2 8}$ & $\mathbf{1 0 0 . 0}$ \\
\hline
\end{tabular}

It was observed that $6(21.4 \%)$ patients had normal serum CA-125. Raised serum CA-125 was found in $22(78.6 \%)$ cases (Table 6).

Table 6: Distribution of the study subjects according to Serum CA-125 Level $(n=28)$

\begin{tabular}{lcc}
\hline Serum CA-125 & Frequency & Percentage \\
\hline Normal & 6 & 21.4 \\
Raised & 22 & 78.6 \\
Total & $\mathbf{2 8}$ & $\mathbf{1 0 0 . 0}$ \\
\hline
\end{tabular}




\section{Discussion}

This cross sectional study was carried out with an aim to evaluate the clinicopathological findings and sociodemographic variables in ovarian cancer. A total of 28 subjects of histopathological proved ovarian tumour age ranging from 13 to 63 years were included in the study who were admitted in the Department of Obstetrics and Gynaecology at BSMMU, DMCH, ShSMCH and BMCH in Dhaka city.

In this study it was found that the mean age was $40.6 \pm 12.5$ years with ranged from 13 to 63 years which is similar age rage (18-80 years) published by Strigini et $\mathrm{al}^{8}$. Maximum number was found in the age group of 41-50 years. Schneider et $\mathrm{al}^{9}$ have shown in their series that the mean age of the subjects having ovarian cancer was 52.6 years with age range from 33 to 71 years and benign ovarian tumor were 48.0 years of age with range from 16 to 76 years, which is higher with the present study. This may be to low life expectancy among the study population of this study.

This study reveals that the presentation of the ovarian tumor is varied. Some of the ovarian tumours may be incidentally diagnosed on ultrasonography whereas others may present with acute abdominal pain. Regarding the symptoms at presentation of the study subjects it was observed that lump (71.4\%) was more common. Weight loss $(60.7 \%)$, heaviness (46.4\%), others symptom $(32.1 \%)$ and pain $(39.3 \%)$ were also frequently recorded symptoms. These results differ with a study carried out at Sir Ganga Ram and Myo Hospital Lahore $^{10}$ where abdominal pain was the commonest presenting complaint $(59.0 \%)$ followed by abdominal mass or distension $(37.0 \%)$. Incessant ovulation is an important determinant of ovarian cancer and factors that suppress ovulation, such as pregnancy, use of oral contraceptive pills (OCP), and lactation play the role in reducing the risk of ovarian cancer ${ }^{11}$. Use of OCP in a life time has been shown to decrease ovarian cancer risk by $40.0 \%$ to $50.0 \%$ compared with never use $\mathrm{e}^{12}$. The reduction in risk appears greatest following more than 10 years of use and demonstrated a clear protective effect of oral contraceptives for ovarian carcinoma ${ }^{13-15}$. Among the patients it was observed that oral contraceptive received $35.7 \%$ patients.

In this study family history of ovarian cancer was found in $14.3 \%$ cases. Epidemiologic studies have indicated that after controlling for age, the strongest risk factor for ovarian cancer is a family history of ovarian cancer ${ }^{16}$. The incidence of ovarian cancer attributable to genetic factors is estimated to be in the range of 5.0 to $10 \%{ }^{16}$. Women with one firstdegree relative with ovarian cancer have a $5.0 \%$ lifetime risk and women with two or more first-degree relatives have a $7.0 \%$ risk $^{17}$. The risk is greater for the sisters and daughters than for the mother ${ }^{17}$. Women with a family history of three or more cases of ovarian cancer are more likely to develop ovarian cancer at an younger age ${ }^{18}$.

In this present study it was observed that $53.3 \%$ used fertility inducing drugs. Use of fertility inducing drugs, family history of ovarian cancer and use of OCP were significantly higher risk of developing ovarian cancer ${ }^{19}$. Infertile women who received fertility drugs for extended period of time are at higher risk of developing ovarian cancer $^{19}$. Overall, multiparous women have a 30 to $70.0 \%$ lower risk as compared with nulliparous women ${ }^{20}$.

Regarding the size of tumor it was observed that 1 to $3 \mathrm{~cm}$ $(7.1 \%), 3.1$ to $5 \mathrm{~cm}(14.3 \%), 5.1$ to $10 \mathrm{~cm}(60.7 \%)$ and more than $10 \mathrm{~cm}(17.9 \%)$ were commonly detected size of the tumor size among the patients. Kawai et $\mathrm{al}^{21}$ and Hamper et $\mathrm{al}^{22}$ had almost same observation.

According to histopathology 28 different malignant tumors were found in this study and serous cyst adenocarcinoma was found in $57.1 \%$ cases, mucinous cyst adenocarcinoma was found in $17.9 \%$, ovarian choriocarcinoma was in $3.6 \%$ cases, endometroid carcinoma was in $3.6 \%$ cases, dysgerminoma was in $7.1 \%$ cases and adenocarcinoma of ovary was in $7.1 \%$ cases. Schneider et $\mathrm{al}^{9}$ observed that serous cysadenocarcinoma was found most commonly $(53.3 \%)$; in addition to that endometrioid carcinoma (26.7\%), mucinous cystadenocarcinoma $(6.7 \%)$ and mixed (combined) type (13.3\%) were also reported, which is comparable with the current study. Among histological types, the commonest category of the ovarian tumours encountered in this series was epithelial tumour followed by germ cell tumours. Serous tumours were found to be more common than mucinous. Similar results were reported by Prabhakar $^{23}$ in which serous tumours were the commonest followed by mucinous tumours.

In this study it was observed that $21.4 \%$ had normal serum CA-125. Raised serum CA-125 was found $78.6 \%$ sujects. Kudoh et $\mathrm{al}^{24}$ observed that $77.6 \%$ malignant ovarian tumor showed raised serum CA-125 which is compatible to this study subjects. The preoperative use of CA-125 tumour markers alone has failed particularly in the early detection of malignancy because of false positive results can be expected along with false negative results ${ }^{25}$.

\section{Conclusion}

Most common clinical presentation of ovarian cancer is lower abdominal lump, weight loss, with feeling of heaviness. Women with multiparity and positive family history were most commonly encountered with ovarian cancer. Both serous and mucinous cyst adenocarcinoma are the common variant of ovarian cancer found in this study. Detailed history, thorough clinical examination and serum CA125 measurement may help in early detection and timely intervention of ovarian cancer can prevent adverse prognosis to some extent.

\section{References}

1. Rodriguez M, Nguyen HN, Averette HE, Steren AJ, Penalver MA, Harrison T, Sevin B. National Survey of Ovarian Carcinoma. XII. Epithelial Ovarian Malignancies in Women Less Than or Equal To 25 Years of Age. Cancer.1994; 73: 1245-1250

2. Pelusi G,Taroni B, Flamigni C. Benign Ovarian Tumors. Frontiers in Bioscience. 1996; 1: 16-19

3. Cutler SJ, Myers MH, Gillor SB. Trends in Survival Rates of Patients with Ovarian Cancer. N Engl J Med.1975; 293: 122-130

4. Tobias JS, Griffiths CT. Management of Ovarian Carcinoma. N Engl J Med.1976; 294: 818-823

5. Young RC, Walton LA, Ellenberg SS, Homesley HD, Wilbanks GD, 
Decker DG, et al. Adjuvant Therapy in Stage I and II Epithelial Ovarian Cancer. Results of Two Prospective Randomized Trials. N Engl J Med.1990; 322: 1021-1027

6. Gereenlee RT, Hill-Harmon MB, Murray T, Thun M, Cancer Statistics. Cancer J Clinic 200; 51: 15-36

7. Di Saia PJ, Creasman WT. Clinical Gynaecological Oncology. 2002; 6 289-350

8. Strigini FAL, Gadducci A, Del Bravo B. Differential Diagnosis of Adnexal Masses Vn Transvaginal Sonography, Color Flow Imaging, and Serum CA-125 Assay In Pre-And Postmenopausal Women. Gynecol Oncol. 1996; 61:68-72

9. Schneider D, Halperin R, Langer R, Bukovsky I, Herman A. Peritoneal Fluid Lactate Dehydrogenase in Ovarian Cancer. Gynecol Oncol .1997; 66: 399-404

10. Rashid S, Sarwar G, Ali A. A Clinicopathological Study of Ovarian Cancer. Departments of Radiotherapy and Oncology Sir Ganga Ram Hospital and Mayo Hospital Lahore. J Pak Med Assoc. 1998; 36: 117-125 11. Purdie DM, Bain CJ, Siskind V, Webb P M, Green A C. Ovulation and Risk of Epithelial Ovarian Cancer. Pint J. Cancer. 2003; 104: 228-232 12. Purdie D, Green A, Bain C. Reproductive and Other Factors and Risk of Epithelial Ovarian Cancer: An Australian Case-Control Study. Int J Cancer. 1995; 62: 678-684

13. Grimes DA, Hughes JM. Use of Multiphasic Oral Contraceptives and Hospitalizations of Women with Functional Ovarian Cysts in the United States. Obstet Gynecol. 1989; 73: 1037-1039

14. Hankinson SE, Colditz GA, Hunter DJ, Spencer TL, Rosner B, Starnpfer ML. Quantitative Assessment of Oral Contraceptive Use and Risk of Ovarian Cancer. Obstet Gynecol. 1992; 80: 708-714

15. Herbst AL. The Epidemiology of Ovarian Carcinoma and the Current Status of Tumor Markers to Detect Disease. Am J Obstet Gynecol 1994; 170: 1099-1107
16. Risch HA, Mclaughlin JR, Cole E, Bradley L, Kwan E, Narod SA. Prevalence and Penetrance of Germline BRCA1 and BRCA2 Mutaions in a Population Series of 649women With Ovarian Cancer. Am J Hum Genet. 2001; 68: 700-710

17. Cook J. Family history of ovarian cancer. Current Obstetrics Gynaecology. 2002;12:47-51

18. Goldberg JM, Piver MS, Jishi MF, Blumenson L. Age at Onset of Ovarian Cancer In Women With A Strong Family History Of Ovarian Cancer. Gynecologyic Oncology.1997; 66: 3-9

19. Rossing M A, Daling J R, Weiss N S. Ovarian Tumors in a Cohort of Infertile Women. New Engl J Med. 1994; 331: 771-776

20. Mosgaard B J, Lidegaard O, Kjaer S K, Schou G, Andersen A N. Infertility; Fertility Drugs; And Invasive Ovarian Cancer: A Case-Control Study. Fertil Steril. 1997; 67: 1005-1012

21. Kawai M, Kano T, Kikkawa F, Maeda O, Oguchi H, Tomoda Y. 'Transvaginal Doppler Ultrasound With Coloue Flow Imaging In The Diagnosis Of Ovarian Cancer. Obstet Gynaecol. 1992; 79: 163-167

22. Hamper UM, Sheth S, Abbas F, M.Rosenshein NP, Aronson D, Kurman RJ. 'Transvaginal Colour Doppler Sonography of Adnexal Masses: Differences in Blood Flow Impedence In Benign And Malignant Lesions.' AJR, 1993; 160:1225-1228

23. Prabarker, Maingi K. Ovarian Tumours--Prevalence in Punjab. Indian J Pathol Microbiol. 1989; 32: 276-281

24. Kondo E, Ogura M, Kagami Y, Taji H, Miura K, Takeuchi T, Maeda S, Asakura S, Suzuki R, Nakamura S, Morishima Y. Assessment Of Prognostic Factors In Follicular Lymphoma Patients. Int J Hematol. 2001; 73: 363-368

25. Markowska J, Kopezynski Z, Szewierski Z, Markowski M, Niecewicz R. The Value of Estimating CA 125 in Fluids from Benign and Malignant Cysts, In the Exudates and Blood Serum in Women with Ovarian Cancer. Eur J Gynaecol Oncol 1994; 15: 29-32 